\title{
EM BUSCA DA SUSTENTABILIDADE ORGANIZACIONAL: A PROPOSICÃO DE UM FRAMEWORK
}

IN SEARCH OF ORGANIZATIONAL SUSTAINABILITY: A PROPOSED FRAMEWORK

EN BUSCA DE LA SOSTENIBILIDAD ORGANIZACIONAL: LA PROPUESTA DE UN FRAMEWORK

\author{
Luciano Munck \\ Doutor \\ Universidade Estadual de Londrina \\ munck@uel.br \\ Ana Claudia Bansi \\ Doutoranda \\ Universidade de São Paulo \\ ana_bansi@hotmail.com \\ Bárbara Galleli Dias \\ Doutoranda \\ Universidade de São Paulo \\ b.gallelidias@gmail.com
}

Flavio Augusto Cella-de-Oliveira Doutorando Universidade Federal do Paraná flaviocella@yahoo.com.br

Submetido em: 22/12/2011 Aprovado em: 19/11/2012

\section{RESUMO}

Este artigo objetiva propor um framework capaz de representar a integração conceitual propiciadora de uma melhor compreensão da sustentabilidade em contexto organizacional. Tal proposição se justifica, pois após uma revisão da literatura sobre desenvolvimento sustentável, sustentabilidade e sustentabilidade organizacional, foi revelada a falta de um quadro teórico explicativo destes, de suas complexidades e de suas viabilizações em organizações. O objetivo de pesquisa demandou uma abordagem metodológica qualitativa, teórica, exploratória e bibliográfica, utilizando-se da análise conceitual. A orientação epistemológica do artigo alinha-se com as perspectivas da Teoria do Agir Organizacional de Maggi (2006), a qual define a organização como um processo de ações e decisões permanente, nunca finalizado, que se dissemina por todos os níveis. Como conclusões, destaca-se a possibilidade de compreender a Sustentabilidade Organizacional como delineadora e orientadora do equilíbrio sistêmico de outras três sustentabilidades: econômica, ambiental e social. Estas, por sua vez, consideradas processos de ações e decisões em constante construção, são delineadas pelo equilíbrio sistêmico advindo da combinação de três subagires organizacionais: ecoeficiência, inserção socioeconômica e justiça socioambiental. Por fim, o framework apresentado orienta as ações organizacionais de uma perspectiva macro, logo, recomenda-se que futuros estudos possam avançar na sua instrumentalização.

PALAVRAS-CHAVE: Framework. Sustentabilidade Organizacional. Agir Organizacional. 


\begin{abstract}
This article proposes a conceptual framework capable of representing the conceptual integration that provides a better understanding of sustainability in an organizational context. This proposal is justified, because after a literature review on sustainable development, sustainability and organizational sustainability, it became apparent that there was a lack of theoretical explanation of these concepts, their complexities and their viabilities in organizations. The goal of research required a qualitative, theoretical, exploratory and bibliographic methodological approach, using conceptual analysis. The epistemological orientation of the article is aligned with the prospects of Maggi's (2006) Theory of Organizational Acting, which describes the organization as a never-ending process of ongoing actions and decisions, which is spread through all levels. As findings, it highlights the possibility of understanding organizational sustainability as a factor for outlining and guiding the systemic balance of three other forms of sustainability: economic, environmental and social. These, in turn, considered processes of actions and decisions always under construction, are outlined by systemic balance arising from the combination of three organizational acting: eco-efficiency, socioeconomic insertion and environmental justice. Finally, the framework presented guides the actions of organizations from a macro perspective, and future studies are recommended that can advance in its instrumentation.
\end{abstract}

KEYWORDS: Framework. Organizational Sustainability. Organizational Acting.

\title{
RESUMEN
}

Este artículo tiene el objetivo de proponer un framework capaz de representar la integración conceptual propiciadora de una mejor comprensión de la sostenibilidad en un contexto organizacional. Tal propuesta se justifica pues tras una revisión de la literatura sobre desarrollo sostenible, sostenibilidad y sostenibilidad organizacional, se reveló la falta de un cuadro teórico explicativo de los mismos, de sus complejidades y de su viabilidad organizacional. El objetivo de esta investigación demandó un abordaje metodológico cualitativo, teórico, exploratorio y bibliográfico, utilizando análisis conceptual. La orientación epistemológica del artículo acompaña las perspectivas de la Teoría del Actuar Organizacional de Maggi (2006), que define la organización como un proceso de acciones y decisiones permanentes, nunca finalizado, que se disemina por todos los niveles. Como conclusión se destaca la posibilidad de comprender la Sostenibilidad Organizacional como delineadora y orientadora del equilibrio sistémico de otras tres sostenibilidades: económica, ambiental y social. Estas, a su vez, consideradas procesos de acciones y decisiones en constante construcción, son delineadas por el equilibrio sistémico que proviene de la combinación de tres subacciones organizacionales: ecoeficiencia, inserción socioeconómica y justicia socioambiental. Por último, el framework presentado orienta las acciones organizacionales desde una perspectiva macro, por lo que se recomienda que estudios futuros puedan avanzar en su instrumentalización.

PALABRAS CLAVE: Framework. Sostenibilidad Organizacional. Acción Organizacional.

\section{INTRODUÇÃO}

Uma revisão crítica da literatura sobre desenvolvimento sustentável, sustentabilidade e sustentabilidade organizacional revela a falta de um quadro global consolidado para a compreensão teórico-aplicada destes termos e de suas especificidades. Uma análise criteriosa mostra que as definições envoltas aos termos são vagas, discordantes em aspectos éticos, ideológicos e práticos, além de carentes de uma base conceitual comum e unificadora, como pode ser observado em diversos trabalhos, como os de Baroni (1992), Rediclif (2007), Vos (2007), Stubbs e Cocklin (2008) e Barkemeyer et al. (2011). Há dúvidas até sobre o que deve ser sustentado, em que tempo e com que interesses (REDCLIF, 2007; VOS, 2007; HOFF, 2008; MUNCK; MUNCK; BORIM-DE-SOUZA, 2011). 
Em análise a diversas conceituações científicas sobre desenvolvimento sustentável, Baroni (1992) constata que há autores que dizem o que este deveria ser, ou o que almejam que ele fosse, e outros autores que confundem desenvolvimento sustentável com sustentabilidade ecológica. Ademais, há autores que reconhecem que deve haver limites para o crescimento econômico, haja vista que ele é insustentável do ponto de vista dos recursos; enquanto outros apenas substituem a compreensão tradicional do desenvolvimento pela do desenvolvimento sustentável. Para Vos (2007), é improvável que em algum momento seja alcançada uma única definição para a questão 'o que deve ser sustentado'. Por estas considerações, Barkemeyer et al. (2011) explicam que os discursos do DS são alvos de inúmeras críticas, dentre as quais destacam-se três: (a) a imprecisão do conceito, devido a suas incontáveis e diferentes interpretações; (b) a abordagem hipócrita ao "rótulo" de desenvolvimento sustentável, tendo em vista sua dificuldade de mensuração criteriosa; e (c) o fato de que o termo é um oxímoro, uma vez que propõe o aumento da industrialização à luz da escassez de recursos naturais e limites ambientais ao crescimento. Contudo, independentemente destas críticas, o desenvolvimento sustentável tornou-se um paradigma orientador na política e na prática.

Outra lacuna encontrada reside na proposição de caminhos para se chegar ao desenvolvimento sustentável ou à sustentabilidade organizacional. De forma geral, estão presentes na literatura as exigências, os indicadores, os efeitos, a história e a crítica. Contudo, verifica-se pouco em relação a como articular esses conceitos sistemicamente para que se tornem ações e decisões organizacionais (MUNCK; MUNCK; BORIM-DE-SOUZA, 2011). Ademais, a materialização do desenvolvimento sustentável em indicadores, mensurações e avaliações torna-se um problema complexo, haja vista que as bases conceituais sobre as questões envolvidas não estão consolidadas (SIENA, 2008).

Todavia, a ausência de qualquer consenso sobre o que o desenvolvimento sustentável representa não significa que o conceito seja inútil e deva ser descartado, mas sim que seu uso requer atenção rigorosa (LENZI; 2005). Em consonância ao entendimento de Meadows, Meadows e Randers (1992), acredita-se que a sustentabilidade constitui uma estratégia de desenvolvimento que resulta na melhoria de qualidade da vida humana e na minimização simultânea dos impactos ambientais negativos. Nesse sentido, é necessária uma gestão integrada, que represente a visão conexa e holística dos aspectos do desenvolvimento social, do crescimento econômico e da proteção ambiental essencial na estratégia de gestão.

Por estas considerações, o presente artigo foi desenvolvido com o objetivo de elaborar uma estrutura conceitual, ou seja, um framework que dê suporte para o entendimento e a viabilização do conceito de sustentabilidade em contexto organizacional, de modo a permitir sua gestão de forma integrada e holística, considerando aspectos sociais, econômicos e ambientais. Para tanto, utilizouse a análise conceitual, que envolve revisões na literatura em busca de padrões e semelhanças, em seguida sintetizaram-se diferentes conceitos, o que permitiu identificar ideias distintas sobre sustentabilidade e circunscrever os conceitos mais adequados para o presente estudo (JABAREEN, 2006; 2009).

Há que se ressaltar as diferenças entre um framework e um modelo. Para Harding e Long (1998), um modelo é uma representação dinâmica da realidade e tem como objetivo esclarecer as relações entre diferentes elementos, indica causalidades e interações efetivas. As características de um modelo fazem parte das características dos frameworks. De acordo com Pinheiro-de-Lima e Lezana (2005), é razoável concluir que um modelo é um tipo particular de framework; no entanto, nem todo framework representa um modelo, e este é o caso do framework que aqui será elaborado. Assim, o objetivo de propor um framework representativo da estrutura compreensiva da sustentabilidade organizacional ganha relevância à medida que os frameworks são utilizados como uma forma de traduzir temas complexos, possibilitando que sejam estudados e analisados (SHEHABUDDEEN; PROBERT; PHAAL, 2000).

Tendo em vista o objetivo deste artigo e em conformidade com o que preza a análise conceitual (JABAREEN, 2006; 2009), a pesquisa realizada pode ser considerada um ensaio teórico, a fim de instigar a reflexão e a interpretação compreensiva da realidade envolta às teorizações da sustentabilidade organizacional (MENEGHETTI, 2011). No Quadro 1 estão elencados os principais temas abordados no artigo, o foco de investigação e os principais autores referenciados. 
Quadro 1 - Estrutura de investigação temática e procedimentos de pesquisa.

\begin{tabular}{|l|l|l|}
\hline $\begin{array}{l}\text { Temas pesquisados por meio } \\
\text { da pesquisa bibliográfica }\end{array}$ & O que investigar? & Principais autores \\
\hline $\begin{array}{l}\text { Desenvolvimento Sustentável } \\
\text { versus Sustentabilidade }\end{array}$ & $\begin{array}{l}\text { Breves comentários sobre contexto } \\
\text { histórico dos conceitos, divergências } \\
\text { de tratamentos e críticas. }\end{array}$ & $\begin{array}{l}\text { WCED (1987); } \\
\text { Van Bellen (2004); } \\
\text { Hoff (2008); } \\
\text { Borim-de-Souza (2010) }\end{array}$ \\
\hline Sustentabilidade Organizacional & $\begin{array}{l}\text { Apresentação de conceitos e } \\
\text { caracterizações que qualificam a } \\
\text { sustentabilidade das organizações. }\end{array}$ & $\begin{array}{l}\text { Van Bellen (2004); } \\
\text { Lins e Zylberstajn } \\
\text { Hockerts (2002) }\end{array}$ \\
\hline Triple Bottom Line & $\begin{array}{l}\text { Abordagem de seu conceito } \\
\text { e componentes derivados: } \\
\text { ecoeficiência, inserção } \\
\text { socioeconômica e justiça } \\
\text { socioambiental. }\end{array}$ & $\begin{array}{l}\text { Savitz e Weber (2007); } \\
\text { Elkington (1999); } \\
\text { Jamali (2006); } \\
\text { Laville (2009) }\end{array}$ \\
\hline $\begin{array}{l}\text { A Sustentabilidade } \\
\text { Agir Organizacional }\end{array}$ & $\begin{array}{l}\text { O desenvolvimento da (re) } \\
\text { construção do conceito }\end{array}$ & $\begin{array}{l}\text { Maggi (2006); } \\
\text { Weber (1964) }\end{array}$ \\
\hline
\end{tabular}

Fonte: Elaborado pelos autores.

Portanto, a fim de alcançar o objetivo aqui proposto, o artigo foi sequenciado nas seguintes seções: introdução, em que o tema foi apresentado, o objetivo do artigo e os procedimentos metodológicos empregados para tal; desenvolvimento sustentável versus sustentabilidade, em que se inserem as explanações acerca da sustentabilidade organizacional e dos pressupostos do Triple Bottom Line, bases deste estudo; na seção seguinte apresenta-se a teoria do agir organizacional; em seguida, é realizada a integração teórica da sustentabilidade organizacional com a teoria do agir organizacional, concretizada na elaboração do framework proposto; e, por fim, são delineadas as considerações finais, implicações para as organizações e sugestões para estudos futuros.

\section{DESENVOLVIMENTO SUSTENTÁVEL VERSUS SUSTENTABILIDADE}

Sabe-se que as proposições da sustentabilidade adquiriram destaque e até tornaram-se uma espécie de mantra para o século XXI. Vê-se, então, a personificação da promessa da evolução da sociedade em direção a um mundo mais socialmente igualitário e repleto de riquezas, em que o meio natural e as conquistas culturais são preservados para as futuras gerações.

O termo desenvolvimento sustentável tornou-se conhecido em 1987, em um documento denominado Relatório Brundtland, publicado no livro Our Common Future, elaborado pela WCED World Commission on Environment and Development, em que é definido como "o desenvolvimento que procura satisfazer as necessidades da geração atual, sem comprometer a capacidade das gerações futuras de satisfazerem as suas próprias necessidades" (WCED, 1987). Na interpretação de Ransburg e Vágási (2007), o desenvolvimento sustentável define uma complexidade de exigências sociais concebidas a fim de manter o desenvolvimento econômico ao longo de gerações, no intuito de promover o uso responsável e eficiente dos recursos naturais, a proteção do meio ambiente e o progresso social, baseado nos princípios dos direitos humanos. Montibeller-Filho (2007) acrescenta que o desenvolvimento sustentável é aquele que se refere a um país ou a uma região, baseado em suas próprias potencialidades, sem criar dependência externa, com a finalidade de responder às questões da harmonização dos objetivos sociais e econômicos do desenvolvimento a partir de uma gestão ecologicamente prudente dos recursos naturais e do meio.

Embora a definição da WCED seja aceita por muitos autores e documentos, esta ideia de desenvolvimento sustentável é alvo de constantes críticas em função da dificuldade de delimitação ou caracterização das necessidades a serem atendidas. Uma crítica advém do que se tem chamado de ética intergeracional, ou seja, como definir o que deve ser gerenciado dentro de uma geração 
e o que perpassa gerações, sendo que as necessidades futuras e os meios para atendê-las ainda não podem ser plenamente estabelecidos. Há também críticas a respeito do conceito de equidade intrageracional por ser subjetivo e por algumas questões que vão além deste conceito, tais como: como fazer o desenvolvimento chegar a todas as pessoas do mundo? Em que padrões de consumo? Em que padrões de bem-estar? (HOFF, 2008).

Ademais, Fergus e Rowney (2005) acreditam que a definição proposta pela WCED não é nada mais do que ambígua, pois retira o foco do que realmente precisa ser feito por meio de um discurso inclusivo, e coloca as prioridades mundiais em simples processos técnicos. Os autores entendem que essa definição é responsável por inviabilizar o agir em prol do alcance do desenvolvimento sustentável.

Neste contexto, no decorrer das mais de duas décadas que se passaram, o debate em torno do assunto acentuou-se, o que levou à revisão até mesmo de seu conceito. Em face disto, diversos autores passaram a tratar desta problemática. Fernandes (2003) apresenta um quadro com vinte diferentes conceitos de sustentabilidade, em que alguns enfatizam características de suas áreas de origem, como as ciências sociais, ciências biológicas, etc., contudo a principal observação que se pode extrair desta situação é a diversidade a e falta de consenso. Porém, apesar de todas as críticas, o Relatório de Brundtland continua a ser apresentado por vários autores (VAN BELLEN, 2004; JACOBI, 2005; HOFF, 2008; SIENA, 2008; MUNCK; BORIM-DE-SOUZA, 2009b; BARKEMEYER et al., 2011) como documento oficial mais aceito na comunidade científica. Para Jacobi (2005, p.7), este relatório "caracteriza-se por seu acentuado grau de realismo, o que o situa como um documento que ao apresentar uma definição oficial do conceito de desenvolvimento sustentável, o faz de forma muito estratégica buscando um tom conciliatório".

Segundo Gladwin, Kenelly e Krause (1995), o desenvolvimento sustentável é entendido como um conjunto de ações de inclusão, integração, igualdade, prudência e segurança. A inclusão sugere o desenvolvimento humano. A integração reconhece a existência de uma interdependência entre os domínios ecológicos, sociais e econômicos. A igualdade busca a justiça intergeracional, intrageracional e interespécies. A prudência investiga os meios de cuidados e prevenção em referência aos atos tecnológicos, científicos e políticos. E a segurança demanda proteção contra ameaças crônicas e contra acontecimentos nocivos.

O desenvolvimento sustentável, na concepção de Jacobi (2005), não se refere especificamente a um problema limitado de adequações ecológicas de um processo social, mas a uma estratégia ou modelo múltiplo para a sociedade, que deve considerar a viabilidade econômica, bem como a ambiental. Num sentido abrangente, a noção de desenvolvimento sustentável remete à necessária redefinição das relações sociedade humana - natureza, e, portanto, a uma mudança substancial do próprio processo civilizatório.

Entretanto, nota-se na literatura que são inúmeros os autores que tratam os conceitos de desenvolvimento sustentável e sustentabilidade como termos análogos. Osório, Lobato e Castillo (2005) combatem também essa generalização, ao afirmarem que as discussões em torno de um debate conceitual não podem ser aceitas como algo óbvio e proveniente de propostas simplistas compostas por definições não muito detalhadas e deficientes de complexidade. De acordo com os autores, assim acontece com o desenvolvimento sustentável e com a sustentabilidade, que se tornaram meras expressões inseridas em um processo inconsciente de homogeneização global. Como consequência, sem uma definição operacional minimamente aceita, torna-se impossível traçar estratégias e acompanhar o sentido e a direção do progresso sustentável (VAN BELLEN, 2004). Além disso, se não for mantida uma coerência discursiva, corre-se o risco de se ceder à generalidade e à ambiguidade presentes nas palavras "desenvolvimento" e "sustentabilidade" (LÉLÉ, 1991).

A sustentabilidade representa um argumento inquestionável, pois independente de seu objetivo final, este deve ser alcançado por um equilíbrio na utilização e no consumo de recursos naturais. A busca de uma sustentabilidade ambiental, por exemplo, é parte integrante de uma meta maior. O desenvolvimento sustentável se baseia na preservação dos recursos naturais, ou seja, busca os mesmos objetivos da sustentabilidade e é complementado pela busca de um equilíbrio social, cultural e econômico (OSORIO; LOBATO; CASTILLO, 2005).

Enquanto a sustentabilidade refere-se à capacidade de manter algo em um estado contínuo, o desenvolvimento sustentável envolve processos integrativos que buscam manter o balanço dinâmico 
de um sistema complexo em longo prazo. A sustentabilidade, então, pode ser considerada a ideia central do desenvolvimento sustentável, uma vez que a origem, os espaços, os períodos e os contextos de um determinado sistema se integram para um processo contínuo de desenvolvimento (JIMÉNEZ HERRERO, 2000).

Conforme tratam Munck e Borim-de-Souza (2009a), cada um indica uma situação diferente. Sustentabilidade é um estado, em que uma organização ou sociedade encontra-se em relação a aspectos econômicos, ambientais e sociais. Comumente quando se diz que uma organização ou uma sociedade é sustentável, deseja-se afirmar que esta é detentora de um determinado nível de sustentabilidade. Para Borim-de-Souza (2010, p. 35), "enquanto a sustentabilidade refere-se à capacidade de manter algo em um estado contínuo, o desenvolvimento sustentável envolve processos integrativos que buscam manter o balanceamento dinâmico de um sistema complexo a longo prazo". É possível compreender, destarte, que é neste sentido em que se situa a maior diferença entre os conceitos: a noção de progresso dinâmico balanceado versus estabilidade alcançada a partir desse tipo de progresso.

Dessa maneira, a sustentabilidade pode ser traduzida como a ideia central perseguida pelo desenvolvimento sustentável, já que a origem, os espaços, os períodos e os contextos de um determinado sistema se integram para um processo contínuo de desenvolvimento (BORIM-DESOUZA, 2010). Munck e Borim-de-Souza (2009b) discutem que o desenvolvimento sustentável e a sustentabilidade buscam os mesmos objetivos, mas o desenvolvimento sustentável deve ser considerado como um caminho para a sustentabilidade.

A partir destas considerações, apesar da reconhecida diferença entre os dois termos, acreditase que na prática eles são complementares, quando se trata da sustentabilidade em âmbito organizacional. Neste contexto, o desenvolvimento sustentável acaba servindo como 'guarda-chuva' geral para várias formas de sustentabilidades e em vários âmbitos (BARKEMEYER et al., 2011). Já a sustentabilidade nas organizações faz que estas sejam um dos atores mundiais que pode fazer sua parte, a fim de se alcançar o desenvolvimento sustentável. A sustentabilidade é desenvolvida nos ambientes internos das organizações a fim de permitir uma gestão coerente que contribua para o alcance do desenvolvimento sustentável (MUNCK; BORIM-DE-SOUZA, 2009a).

Para que haja tal forma de gestão, dentre as diversas abordagens existentes, Munck e Borimde-Souza (2009a) ressaltam que é preciso que o foco esteja nos três pilares viabilizadores da sustentabilidade: o pilar econômico, o ambiental e o social, uma vez que estas são as bases do fenômeno. O conjunto de ações citado por Gladwin, Kenelly e Krause (1995), assim como o processo civilizatório apontado por Jacobi (2005), também é delineados a partir desta abordagem tripartite. A referida abordagem em pilares foi cunhada por Elkington (1999) e denominada como Triple Bottom Line, e será abordada de forma aprofundada no próximo item.

Estudados os principais pontos do desenvolvimento sustentável e da sustentabilidade, partese para a próxima seção, a qual trata de um dos temas de maior interesse deste trabalho, a sustentabilidade organizacional.

\section{Sustentabilidade Organizacional e os pressupostos do Triple Bottom Line}

Como o enfoque do artigo paira sobre a amplitude das organizações, ao pesquisar a sustentabilidade em contexto organizacional, é possível deparar-se com diferentes denominações, dentre as quais sustentabilidade corporativa (AZAPAGIC, 2003; Van MARREWIJK, 2003), sustentabilidade empresarial (SILVA; QUELHAS, 2006; GIL LAFUENTE; PAULA, 2011) e sustentabilidade organizacional (ELKINGTON, 1999; SAVITZ; WEBER, 2007; MUNCK; MUNCK; BORIM-DE-SOUZA, 2011). Contudo, adotou-se para este artigo, assim como para o conceito que será apresentado, o termo sustentabilidade organizacional, por entender este como amplo o suficiente para envolver as demais definições. Tal fato, em um primeiro momento, permite que ele seja aplicado a diversos tipos de organizações, não somente às privadas, mas também governamentais e sociais, por exemplo.

Com a emergência do debate sobre desenvolvimento sustentável em escala mundial, diversas nações iniciaram estudos para adotarem e estimularem a sustentabilidade organizacional, conforme comentam Atkinson, Hett e Newcombe (1999). A natureza destas discussões demanda 
operacionalização e contextualização e, nesse sentido, o setor privado tem um papel fundamental (BARKEMEYER et al., 2011). As organizações são causadoras de amplos impactos e de extrema influência na sociedade contemporânea nacional ou internacional (WHEELER et al., 2005), bem como constituem simultaneamente o principal 'consumidor' dos recursos ambientais e gerador de capital econômico (BARKEMEYER et al., 2011), por estas razões possuem papel imprescindível para o alcance da sustentabilidade.

Portanto, ao partir de um enfoque organizacional do desenvolvimento sustentável, vários autores como Van Marrewijk (2003); Silva e Quelhas (2006); Jamalli (2006); Savitz e Weber (2007); Hoff (2008); Lemme (2010) e Dias et al. (2011) partem do princípio de que a sustentabilidade organizacional deve buscar um equilíbrio entre o que é socialmente desejável, economicamente viável e ecologicamente sustentável. Assim, este conceito induz a um novo modelo de gestão de negócios que envolve, além da dimensão econômico-financeira, as dimensões ambiental e social.

De acordo com Savitz e Weber (2007), a organização é sustentável quando gera lucro para os acionistas, protege o meio ambiente e melhora a vida das pessoas com quem mantém interações. Dyllick e Hockerts (2002) definem a sustentabilidade organizacional como a capacidade de as organizações alavancarem seus capitais econômico, social e ambiental ao contribuírem para o desenvolvimento sustentável em seu domínio político. A sustentabilidade organizacional, então, é concernente à forma de se fazer negócios, bem como ao tipo de negócios que uma organização pretende desenvolver (LINS; ZYLBERSZTAJN, 2010).

Desta forma, uma organização sustentável exprime o seu propósito, visão e/ou missão em termos de resultados sociais, ambientais e econômicos, fazendo com que os conceitos de sustentabilidade desempenhem um papel incondicional na tomada de decisão organizacional. Com essa perspectiva em mente, os lucros são um 'meio' para alcançar resultados sustentáveis, ou seja, as organizações devem buscar a existência de lucratividade, mas elas precisam buscar, acima de tudo, a sustentabilidade (STUBBS; COCKLIN, 2008).

Pela consideração de que ao exercer suas atividades as organizações consomem não só recursos financeiros, mas também ambientais e sociais, Elkington (1999) propôs o relacionamento entre os três pilares da sustentabilidade (social, econômico e ambiental), conhecidos na literatura como Triple Bottom Line - TBL, o qual traduz uma perspectiva de análise da sustentabilidade cada vez mais aceita pela sociedade e pelas organizações. Vale ressaltar, conforme as afirmações de Dyllick e Hockerts (2002), que estes três pilares possuem diferentes propriedades e por isso requerem diferentes abordagens. Laville (2009) comenta que a principal evidência deste modelo é a de que a organização não deve basear suas decisões em apenas um dos pilares, uma vez que tal fato pode acarretar o insucesso de qualquer estratégia organizacional de longo prazo.

A partir da constatação de que as ações organizacionais não devem ser consideras sustentáveis quando atenderem, ainda que eficientemente, a apenas um ou outro pilar da sustentabilidade, emerge a necessidade de integrá-los. O próprio conceito de sustentabilidade organizacional proposto pelo TBL (ELKINGTON, 1999) já prevê a integração. A consolidação da proposta do TBL, na visão de Oliveira (2002), compreende o questionamento e o repensar do gerenciamento de respostas e ações organizacionais ao meio que a circunda, enfatizando as funções social e ambiental das organizações como componentes de um sistema integrado à sociedade.

Savitz e Weber (2007) ainda argumentam que a estrutura do TBL capta a essência da sustentabilidade organizacional, ao permitir medir o impacto socioambiental das atividades operacionais das organizações. Quando o resultado apresenta-se positivo, reflete aumento no valor da organização, em termos de lucratividade e de contribuição para a riqueza dos acionistas, bem como no aspecto de seu capital social, humano e ambiental. A Figura 1 visa clarificar os elementos componentes da sustentabilidade organizacional, adaptando as abordagens de Savitz e Weber (2007) e Elkington (1999). 
Figura 1: Elementos da sustentabilidade organizacional

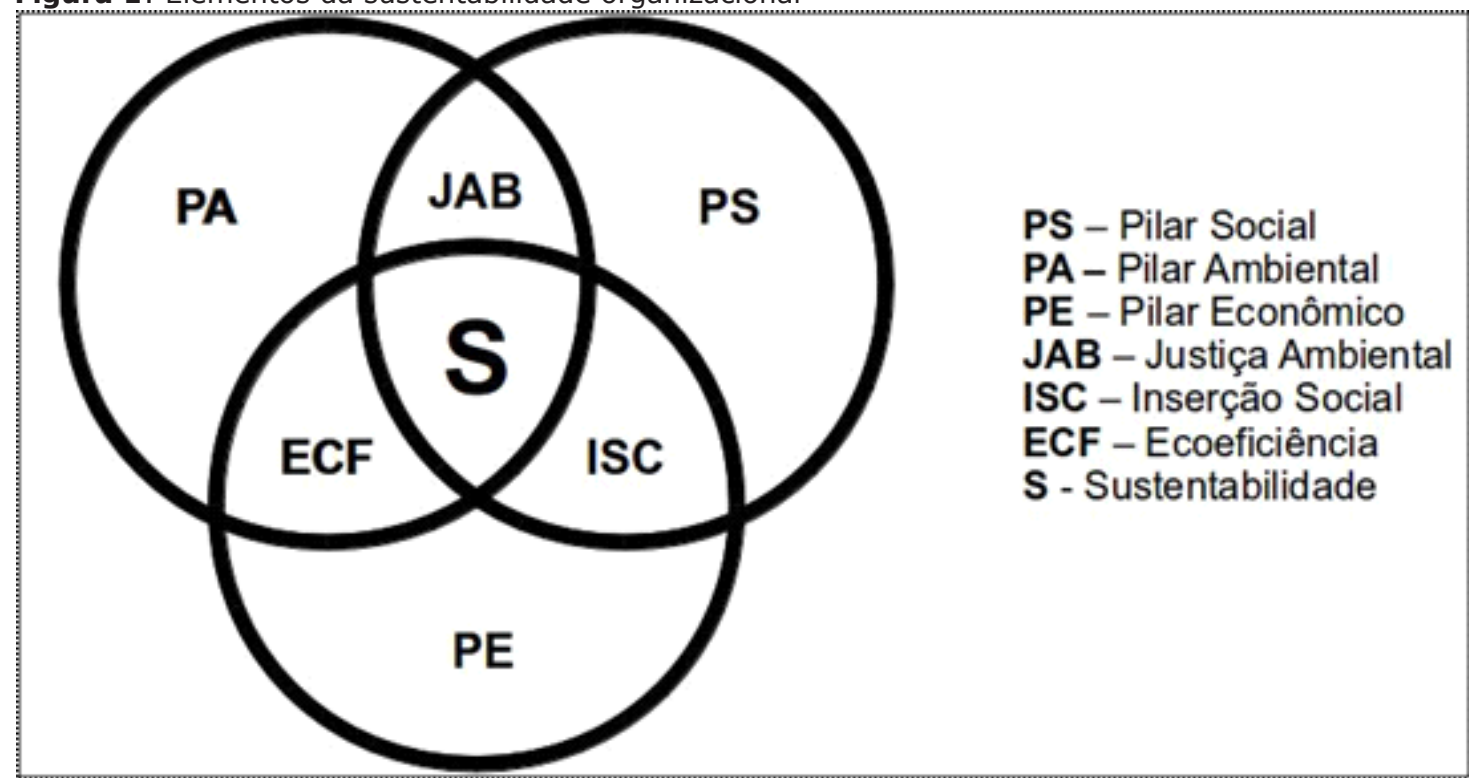

Fonte: Elaborada pelos autores a partir Savitz e Weber (2007) e Elkington (1999).

No intuito de detalhar um pouco mais as explicações acima, no que diz respeito aos três pilares componentes da sustentabilidade organizacional, encontra-se em Lorenzetti, Cruz e Ricioli (2008) que o pilar econômico refere-se ao impacto das organizações sobre as condições econômicas das partes interessadas e sobre o sistema econômico em todos os níveis, ou seja, representa a geração de riqueza pela e para a sociedade, por meio do fornecimento de bens e serviços. Neste pilar, é aceitável que a organização realize suas atividades de maneira responsável e reconhecida, com retorno econômico e social para os envolvidos (MUNCK; MUNCK; BORIM-DE-SOUZA, 2011). Segundo Azapagic (2003), a viabilidade econômica do negócio é peça central da sustentabilidade, pois, por meio do lucro, são promovidos empregos, por meio dos quais é proporcionada à comunidade a possibilidade de alcançar melhores condições de vida.

Já o pilar ambiental refere-se à conservação e ao manejo dos recursos naturais. É necessário que a organização, sob a perspectiva dos impactos de suas operações e produtos sobre os sistemas naturais vivos e não vivos, procure minimizar os impactos negativos e amplificar os positivos, tanto em processos de entrada quanto de saída (KRANJC; GLAVIC, 2005). A responsabilidade sobre o meio natural abrange mais do que cumprimentos legais ou iniciativas como reciclagem ou uso eficiente de recursos energéticos. Envolve, antes, uma abordagem compreensiva sobre as operações organizacionais (JAMALI, 2006).

Por fim, o pilar social, de acordo com Lorenzetti, Cruz e Ricioli (2008), diz respeito ao alcance da igualdade e da participação de todos os grupos sociais na construção e na manutenção do equilíbrio do sistema, compartilhando direitos e responsabilidades. Para as organizações, refere-se ao seu impacto no sistema social no qual operam; o desempenho social é abordado por meio desta análise sobre as partes interessadas em nível local, nacional e global. Segundo Azapagic (2003) e Munck, Munck e Borim-de-Souza (2011), o pilar social para as organizações representa a preocupação com o desenvolvimento humano e bem-estar (educação e treinamento, saúde e segurança, etc.); equidade (salários e benefícios, oportunidades iguais e não discriminação); e considerações éticas (direitos humanos, valores culturais e justiça intergeracional).

Fundamentando-se em Elkington (1999) e Savitz e Weber (2007), a integração dos três pilares supra faz emergir intentos organizacionais que representam a integração e os meios de viabilização dos três pilares. São eles Inserção Social, Ecoeficiência e Justiça socioambiental (ELKINGTON, 1999; SAVITZ; WEBER, 2007):

- Inserção Social - representante e viabilizadora do alcance balanceado dos pilares econômico e social, pela qual se busca, coletivamente, proporcionar a todos o acesso à informação, à alimentação, 
à saúde, à educação, à habitação, à renda e à dignidade;

- Ecoeficiência - representante e viabilizadora do alcance balanceado dos pilares econômico e ambiental, pela qual se intenta a prosperidade econômica por meio do uso eficiente dos recursos naturais e da redução de emissões danosas ao ambiente; e

- Justiça Ambiental - representante e viabilizadora do alcance balanceado dos pilares social e ambiental, pela qual se intenta a equalização da distribuição dos benefícios e dos constrangimentos impostos pela legislação ambiental, ambiente de trabalho, ou mesmo pelos problemas ambientais, entre diferentes grupos sociais.

Vistas as considerações fundamentais sobre a sustentabilidade organizacional e sobre o Triple Bottom Line (sendo este uma das bases conceituais do framework proposta), faz-se necessária uma breve referência à Teoria do Agir Organizacional, pivô teórico do presente artigo para a elaboração da estrutura conceitual que almeja dar suporte para o entendimento e para a viabilização do conceito de sustentabilidade organizacional.

\section{BASES CONCEITUAIS PARA A SUSTENTABILIDADE ORGANIZACIONAL: O AGIR ORGANIZACIONAL}

Ao se observar brevemente considerações acerca das Teorias Contingencial e Institucional, observa-se que ambas falham ao considerar o aspecto subjetivo inerente às ações organizacionais, embora a última traga à tona as organizações informais e a racionalidade substantiva o faz de maneira superficial. Donaldson (1999) argumenta que as contingências possuem alguma influência, mas há um grau considerável de escolha feita pelo administrador, conceituada "escolha estratégica".

Em consonância, Machado-da-Silva e Gonçalves (1999) afirmam que a percepção dos tomadores de decisão sobre escolhas estratégicas depende da convergência entre as expectativas e o resultado efetivo das ações organizacionais, o que pode levar a tendência à inércia organizacional ou à predisposição ou mesmo à necessidade de mudança. Administradores podem variar em suas respostas às contingências, bem como às pressões institucionais, de acordo com suas percepções, preferências, valores, interesses e poder, fatores estes que em nível de ação ganham força e espaço em virtude da fraqueza do imperativo dos sistemas.

A Teoria do Agir Organizacional, de Maggi (2006), apresenta-se válida para sua aplicação na organização de modo coerente com a proposta deste artigo. Para o autor, uma teoria é uma construção formada de conceitos e hipóteses, constituindo um ponto de vista. A teoria do agir organizacional, desse modo, exprime, dentre tantas outras, uma maneira de ver e conceber os fenômenos organizacionais de forma interdisciplinar, cujos fundamentos epistemológicos estão estruturados de acordo com contribuições de autores considerados clássicos da Sociologia e da Teoria Organizacional, como de Max Weber, Chester Barnard, Hebert Simon, James Thompson, JeanDaniel Reynaud e Anthony Giddens. Portanto, como será visto, configura uma teoria organizacional abrangente, capaz de incorporar contextos maiores dos aspectos socioambientais.

Um dos maiores influenciadores da Teoria do Agir Organizacional é Max Weber (1964), que indicou uma "terceira via" que busca conciliar ou encontrar um meio termo em relação aos extremos entre a explicação positivista e a compreensão que rejeita qualquer explicação (antipositivista). A abordagem de Weber desenvolve, ao mesmo tempo, a compreensão do sentido subjetivo do agir e a explicação dos fenômenos sociais por meio de procedimentos objetivos e verificáveis. A epistemologia weberiana coloca em evidência as maneiras pelas quais condições objetivas se tornam causas efetivas, por meio do agir intencional dos sujeitos agentes.

Desta forma, o Agir Organizacional caracteriza-se como um agir social, definido por Weber (1964) como a atitude humana que se orienta em relação à atitude de outros indivíduos ao longo de seu curso. A partir dessa concepção, Maggi (2006) compreende a organização como um agir social, como um processo de ações e decisões. Essa concepção não separa a organização dos sujeitos agentes que nela atuam e desenvolvem o processo em acordo com sua racionalidade intencional e limitada. Assim, o agir organizacional caracteriza-se como um agir social em que os processos e o tempo são fundamentais, organização e sujeito agente não são separáveis, as ações são compostas 
pelas decisões as quais indicam relação entre conduta e sentidos subjetivo e objetivo de um sujeito humano. Portanto, as organizações são vistas como forma de agir e, consequentemente, como um processo de ações e decisões dirigidas ao fim de produzir uma ordem, ou seja, regras.

Outro ponto interessante da teoria do agir organizacional é que a interpretação e a avaliação desta teoria não estarão completas se não considerarem vantagens e desvantagens que delas decorrem para o sujeito agente. Acredita-se que uma avaliação expandida deve considerar o bem-estar dos sujeitos envolvidos, em seu sentido mais amplo: bem-estar físico, mental e social. Como visto, no escopo da Teoria do Agir Organizacional, a visão da organização como processo de ações e decisões implica um sujeito agente não separável da ação. Desse modo, o sujeito ao situar-se no centro do processo, em sua construção e desenvolvimento, seu bem-estar está necessariamente em pauta e depende inteiramente da avaliação da harmonia do processo organizacional (MAGGI, 2006).

Em suma, Maggi (2006, p. 8) explica os pilares do agir organizacional a partir da descrição da execução da obra Octeto em fá maior D803, de Schubert, para dois violinos, viola, violoncelo, contrabaixo, clarinete, fagote e trompa, da seguinte forma:

[...] estamos na presença de um trabalho coletivo, qualquer que seja a definição que se dê a essa noção; e na presença de um grupo de trabalho, o conjunto. [...] a ação de cada músico dirige-se à ação dos outros músicos, e a de todos se dirige no mínimo à administração do teatro e ao público presente na sala. [...] o processo de ação de cada sujeito, assim como o processo comum do conjunto, está relacionado a outros processos. [...] a adaptação dos meios aos fins concerne, sem dúvida, aos instrumentos que a composição musical exige, mas também ao nível das capacidades, dos conhecimentos e das competências dos músicos, e ao tempo que dedicaram aos ensaios. [...] os músicos parecem dominar completamente os meios e os fins, mas a incerteza jamais será excluída, não se sabe o que pode acontecer. [...] o que faz a diferença é que cada músico queria tocar essa obra, mas não podia fazê-lo sozinho. [...] sendo a execução da música o objetivo comum, os oito músicos cooperam para atingi-lo. E, para que essa cooperação dê certo, eles se coordenam.

Diante da breve exemplificação, pode-se inferir que as características centrais do agir organizacional em diferentes situações são a finalização, que constitui a compreensão da relação meios/fins/resultados; a estruturação do processo, que envolve a articulação de processos e o entendimento das ações como racionalmente limitadas e intencionais. Além disso, percebe-se que a cooperação influencia o poder das ações, que por consequência influencia a efetividade das decisões, a qual por seu turno age sobre as estratégias organizacionais e os relacionamentos sociais (MAGGI, 2006).

Justifica-se assim a teoria do agir organizacional como uma forma de ver a organização mais aproximada da estrutura conceitual aqui proposta. A maneira de conceber as organizações como processos de ações de decisões traz à tona a participação dos indivíduos como fundamentais para que os objetivos organizacionais sejam alcançados, o que também é aceito como preceito básico neste estudo. Além deste estudo, alguns outros já publicados em eventos científicos e periódicos do cenário nacional baseiam-se na teoria de Maggi para o entendimento dos fenômenos envoltos à S.O., o que confere indícios de sua viabilidade, tais como Munck e Borim-de-Souza (2009a), Borim-de-Souza (2010), Munck, Munck e Borim-de-Souza (2011), Dias et al. (2011) e Cella-deOliveira (2012).

\section{A SUSTENTABILIDADE ORGANIZACIONAL SOB O PRISMA DO AGIR ORGANIZACIONAL: A (RE)CONSTRUÇÃO DE CONCEITOS}

O modelo de Sustentabilidade Organizacional a ser apresentado busca, sobre a égide da Teoria do Agir Organizacional e orientações sobre a sustentabilidade organizacional advindas de Elkington (1999); Dyllick e Hockerts (2002); Savitz e Weber (2007) e Munck, Munck e Borim-de-Souza (2011), criar uma estrutura conceitual capaz de fornecer uma opção às organizações que estão em busca da sustentabilidade organizacional (Figura 1). Tal estrutura conceitual representa um conjunto de preceitos básicos e genéricos. Uma vez reconhecidas as bases deste modelo, cabe à organização estruturar ferramentas de gestão particulares com vistas a alavancar e a desenvolver cada um de seus elementos. Assim, ressalta-se que a presente estrutura tem caráter orientador e apresenta elementos necessários ao processo decisório e integrador em favor da sustentabilidade organizacional. 
Antes de conceituar os itens da estrutura conceitual proposta, é preciso que haja um nivelamento na compreensão em torno de um conceito, assim, a discussão caminha para o entendimento do que é um conceito, ou seja, para a definição de conceito a ser utilizado. A partir das características expostas por Jabareen (2009), ainda é necessária a formulação de uma definição para o termo conceito, assim se recorre a Abbagnano (2007, p. 164), que exprime o seguinte:

\begin{abstract}
Conceituar, em geral, expressa todo o processo que torne possível a descrição, a classificação e a previsão dos objetos cognoscíveis (que se pode conhecer). Embora o Conceito seja normalmente indicado por um nome não é o nome, já que diferentes nomes podem exprimir o mesmo Conceito ou diferentes conceitos podem ser indicados, por equívoco, pelo mesmo nome. A função primeira e fundamental do Conceito é a mesma da linguagem, isto é, a comunicação.
\end{abstract}

Como o presente artigo trata da construção de uma estrutura conceitual, é preciso avançar mais um passo, a fim de entender seu conceito e suas características. Utilizar os termos estrutura conceitual ou estrutura teórica, por si só, é muito vago e impreciso, de acordo com Jabareen (2009, p. 51), por isso o autor tenta definir estes termos e conclui que "estrutura conceitual é uma rede interligada de conceitos que provê a compreensão e entendimento de um fenômeno". Sobre a estrutura conceitual, ainda, o autor a caracteriza da seguinte forma:

- Uma estrutura conceitual, também entendida como framework, não é apenas uma coleção de conceitos, mas uma construção na qual cada conceito tem seu papel;

- Apresenta não uma definição causal/analítica, mas uma abordagem interpretativa da realidade social;

- Em vez de oferecer explicações teóricas, como modelos quantitativos, se preocupa com a compreensão e o entendimento;

- Visualiza o conhecimento como hard, mas possibilita facilidade nas interpretações;

- Não é de natureza determinística, assim, não permite a previsão de resultados;

- Estruturas conceituais podem ser desenvolvidas a partir de análises qualitativas;

- Os dados advêm de várias outras teorias que passam então a ser dados empíricos.

Com base nas fundamentações apresentadas até aqui a respeito do debate em torno de modelo e estrutura conceitual ou framework (HARDING; LONG, 1998; PINHEIRO-DE-LIMA; LEZANA, 2005; JABAREEN, 2009), pode-se categorizar o resultado do estudo, apresentado na Figura 2, como um framework aqui entendido como integrador e viabilizador da sustentabilidade organizacional.

Figura 2 - Framework da Sustentabilidade Organizacional

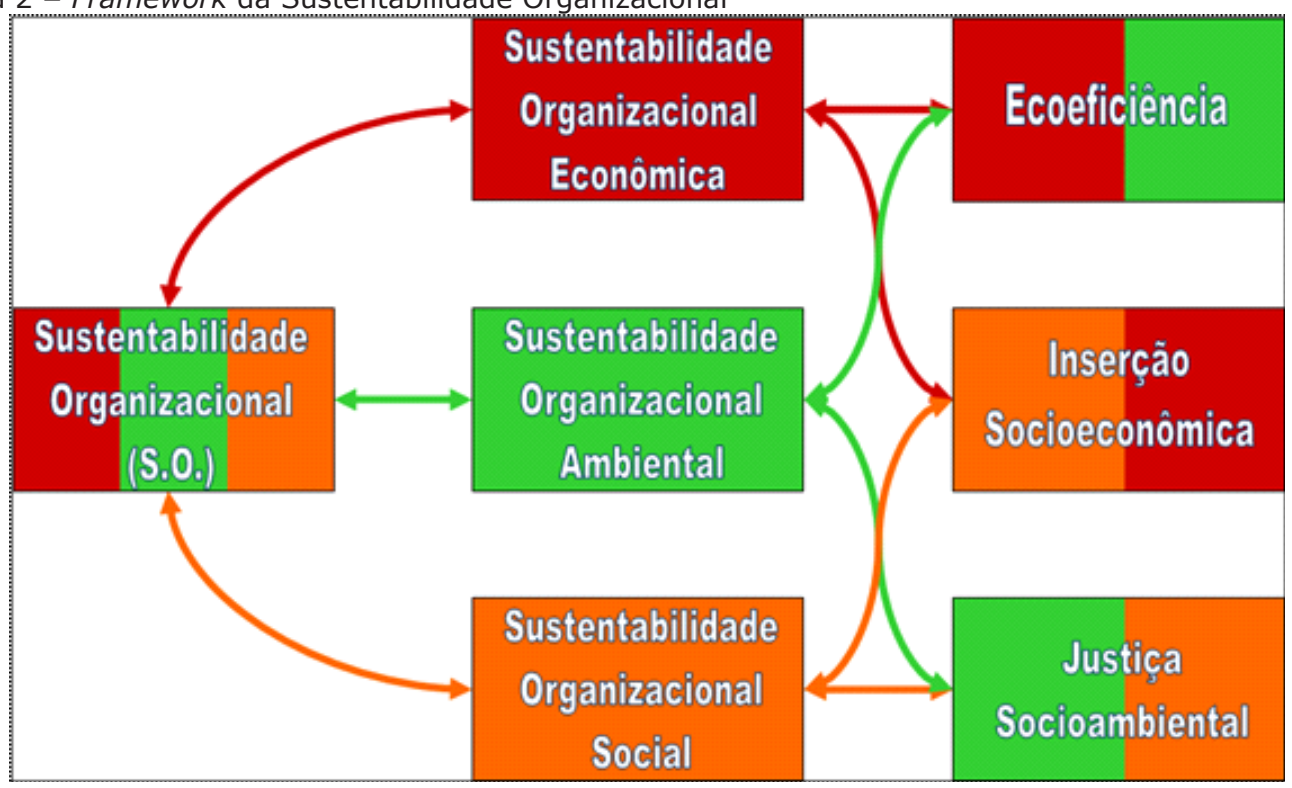

Fonte: Elaborada pelos autores a partir das contribuições dos autores pesquisados. 
Neste framework da Sustentabilidade Organizacional almejando jogar luz na integração dos pilares, conforme visto da Figura 1, bem como dar-Ihes mais evidência conceitual e prática, convencionou-se aqui, utilizando como bases os referenciais estudados, converter os pilares da sustentabilidade organizacional em três sustentabilidades: organizacional econômica, organizacional ambiental e organizacional social. As três sustentabilidades tornam-se então sustentadoras e viabilizadoras da sustentabilidade organizacional. Estudos que se utilizam da mesma terminologia (DILLICK; HOCKERTS, 2002; JAMALI, 2006; KRANJC; GLAVIC, 2005) permitem concluir que os três pilares estão implícitos nas três sustentabilidades organizacionais propostas, todavia, em proporções diferentes. Para alcançar o estado da sustentabilidade, portanto, nessa estrutura conceitual, uma organização deve antes desenvolver suas sustentabilidades econômica, ambiental e social, de maneira equilibrada e conforme o contexto da organização.

Tem-se, portanto, que a sustentabilidade econômica representa a geração de riqueza pela e para a sociedade, por meio do fornecimento de bens e serviços, de maneira responsável e reconhecida, é atingida pela realização da ecoeficiência e da inserção socioeconômica. A sustentabilidade ambiental refere-se à minimização dos impactos negativos e à ampliação dos positivos, por uma abordagem compreensiva sobre as operações organizacionais, concretizada pela realização da ecoeficiência e da justiça socioambiental. A sustentabilidade social concerne à promoção da igualdade, do desenvolvimento humano e bem-estar e da busca pela participação de todos os grupos sociais na construção e na manutenção do equilíbrio do sistema em que operam as organizações, é atingida pela realização da inserção socioeconômica e da justiça socioambiental. Por realização entende-se o alcance dos indicadores definidos para cada um dos componentes das três sustentabilidades: ecoeficiência, inserção socioeconômica e justiça socioambiental, cujos desenvolvimentos demandam um novo estudo, mais aprofundado.

As sustentabilidades social, ambiental e econômica devem confluir de forma articulada para a concretização da sustentabilidade organizacional e, por conseguinte, do desenvolvimento sustentável (CALLADO, 2010). Dessa maneira, é possível inferir que uma visão equilibrada a respeito de como articular e fazer uso dos recursos provenientes destas três esferas é essencial para se garantir às gerações futuras uma sociedade economicamente próspera, regida por princípios de justiça e com melhor qualidade ambiental e de vida.

No framework apresentado, portanto, emerge o necessário alinhamento de seus componentes, uma vez que os processos ocorrem em virtude de sua relação balanceada com os ambientes externos e internos. Em pesquisas relacionadas à estratégia, o alinhamento denota agrupamento, coesão, ajuste e congruência entre diferentes dimensões, podendo ser discutido simultaneamente como processo e resultado, bem por isso é assumido como uma dinâmica de ajuste da organização com o ambiente, ou como um mecanismo de mobilização dos recursos organizacionais em função da interatividade inerente aos processos estratégicos (GALBRAITH; KAZANJIAM, 1986). É, portanto, por este alinhamento que é determinado o relacionamento entre os componentes do framework.

A interação das definições presentes na estrutura conceitual demonstrativa do conceito de Sustentabilidade Organizacional ocorre em consonância com as premissas da teoria do agir organizacional proposta por Maggi (2006). A Teoria de Maggi (2006) prevê uma perspectiva sistêmica, que delineia a interdependência dos elementos da estrutura, em que o mínimo abalo de um dos elementos é capaz de desbalancear toda a estrutura. É por este motivo que a estrutura, embora graficamente lembre uma estrutura hierárquica, não possui nenhuma pretensão desta natureza. Desta forma, este caráter sistêmico é representado pelas setas duplas, nas quais se evidencia a interdependência dos elementos, bem como suas interações, as quais ocorrem nos dois sentidos, e todos os elementos são dependentes um do outro. Como já dito, a alteração em qualquer um destes elementos é capaz de alterar o equilíbrio de todo o sistema, assim como previsto pela estruturação do processo da Teoria do Agir Organizacional, exemplificado anteriormente por meio do Octeto de Schubert.

Para o acontecimento da sustentabilidade organizacional é preciso haver o desenvolvimento balanceado das sustentabilidades organizacionais: econômica, ambiental e social, as quais serão viabilizadas e integradas pelo desenvolvimento otimizado dos fenômenos ecoeficiência, justiça socioambiental e inserção socioeconômica. Assim, mediante esta estruturação, o retrocesso no desenvolvimento de um destes elementos é capaz de desbalancear todo o sistema. Este processo, 
ao longo do tempo, reelabora autonomamente suas regras conforme aponta Maggi (2006), por meio do processo de finalização (compreensão dos meios, fins e resultados), também exemplificado pelo autor por meio do Octeto de Schubert.

Além disso, destaca-se que o framework proposto prima por um estágio ideal de desenvolvimento. Contudo, as organizações podem iniciar o processo de desenvolvimento buscando o equilíbrio proposto pela estrutura apresentada ou tomando-o como referência. Portanto, as organizações não iniciam o processo do zero. Provavelmente alguns elementos já estarão desenvolvidos e necessitarão de menores esforços. Observa-se que não é permitido à organização trabalhar apenas em um dos elementos isoladamente, haja vista que a estrutura se constrói de forma integral e sistêmica. Esta proposta de construção/desenvolvimento dos elementos de forma concomitante também é discutida por Maggi (2006). A situação é análoga àquela exemplificada no Octeto de Schubert, em que cada músico gostaria de tocar a obra, mas não poderia fazê-lo sozinho.

A partir destas elucidações, percebe-se que todo o framework é circundado pelo agir organizacional, contudo, com vistas a uma divisão didática, entende-se a sustentabilidade organizacional econômica, ambiental e social como agires organizacionais capazes de conduzir a organização a um estado de sustentabilidade. Por conseguinte, tem-se que o resultado da interação entre as três sustentabilidades (que passam a ser denominadas como fenômenos de relacionamento: ecoeficiência, inserção socioeconômica e justiça socioambiental) são entendidos como subagires organizacionais, vitais ao processo de desenvolvimento do framework como um todo.

O entendimento destes elementos como agires e subagires ocorre em razão de que são advindos da própria organização, a qual é um agir em si. Este agir organizacional é composto por um processo de ações e decisões, dotados de racionalidade intencional e limitada. Como a sustentabilidade faz parte de um processo maior (uma organização) e está diretamente dependente dos processos desta, pode também ser caracterizada como um agir organizacional.

Postas as considerações para entendimento do funcionamento da estrutura apresentada, no Quadro 2 são dispostos os conceitos de cada um dos elementos presentes no framework da Figura 2 , os quais foram formulados a partir da definição de conceito de Abbagnano (2007), assim como o processo de interação destes agentes.

Quadro 2: Definição conceitual dos elementos do modelo de sustentabilidade apresentada.

\begin{tabular}{|c|c|}
\hline $\begin{array}{l}\text { Elemento } \\
\text { conceitual }\end{array}$ & Definição \\
\hline $\begin{array}{l}\text { Sustentabilidade } \\
\text { Organizacional } \\
\text { (S.O.) }\end{array}$ & $\begin{array}{l}\text { Representação sistêmica do equilíbrio dos agires organizacionais: sustentabilidades } \\
\text { econômica, ambiental e social. Neste contexto, entende-se por equilíbrio o } \\
\text { balanceamento de investimentos e resultados nas três sustentabilidades (econômica, } \\
\text { ambiental e social) em acordo com os objetivos organizacionais. Por representação } \\
\text { sistêmica, o entendimento é a conjunção das três sustentabilidades, resultando assim } \\
\text { a sustentabilidade organizacional. }\end{array}$ \\
\hline S.O. Econômica & $\begin{array}{l}\text { Subsistema da S.O. que representa a realização da ecoeficiência e da inserção } \\
\text { socioeconômica. Entende-se por realização o alcance dos indicadores definidos para } \\
\text { medição da ecoeficiência e da inserção socioeconômica. }\end{array}$ \\
\hline S.O. Ambiental & $\begin{array}{l}\text { Subsistema da S.O. que representa a realização da justiça socioambiental e ecoeficiência. } \\
\text { Entende-se por realização o alcance dos indicadores definidos para medição da justiça } \\
\text { socioambiental e ecoeficiência. }\end{array}$ \\
\hline S.O. Social & $\begin{array}{l}\text { Subsistema da S.O. que representa a realização da justiça socioambiental e inserção } \\
\text { socioeconômica. Entende-se por realização o alcance dos indicadores definidos para } \\
\text { medição da justiça socioambiental e inserção socioeconômica. }\end{array}$ \\
\hline Ecoeficiência & $\begin{array}{l}\text { Subagir organizacional que combina o desenvolvimento ambiental com o } \\
\text { desenvolvimento econômico, ao mesmo tempo em que reduz os impactos ambientais } \\
\text { e promove a utilização racional dos recursos naturais. }\end{array}$ \\
\hline $\begin{array}{l}\text { Inserção } \\
\text { Socioeconômica }\end{array}$ & $\begin{array}{l}\text { Subagir organizacional, com influência no ambiente interno e externo, que garante, aos } \\
\text { indivíduos, recursos suficientes para o seu acesso a oportunidades e desenvolvimento } \\
\text { equitativo frente aos objetivos organizacionais. }\end{array}$ \\
\hline $\begin{array}{l}\text { Justiça } \\
\text { Socioambiental }\end{array}$ & $\begin{array}{l}\text { Subagir organizacional que assegura aos indivíduos o recebimento equilibrado e } \\
\text { contextual dos malefícios e dos benefícios sociais e ambientais advindos das atividades } \\
\text { organizacionais. }\end{array}$ \\
\hline
\end{tabular}


Algumas diferenças são visualizadas nos elementos deste framework em relação aos autores citados na revisão bibliográfica (tópicos 3 e 3.1). Primeiramente, o entendimento dos três pilares da sustentabilidade, apresentados originalmente por Elkington (1999), são entendidos, no contexto organizacional, já mencionado previamente, como sustentabilidades econômica, ambiental e social, uma vez que desta forma permite-se abranger todos os processos econômicos, ambientais e sociais envolvidos pelas atividades organizacionais de maneira integrada. São ainda entendidos como sustentabilidades uma vez que, assim, adquirem a capacidade de representar estados de desenvolvimento, ou seja, são capazes, a partir de então, de demonstrar qual o estado de desenvolvimento de cada um, excluindo-se a perspectiva estável e imutável.

Os fenômenos de relacionamento são expandidos a fim de uma melhor compreensão do funcionamento da estrutura. A ecoeficiência deixa de ser compreendida da forma comumente encontrada na literatura, ou seja, como uma mera política empresarial de redução de custos e, ainda, com caráter imediatista, e passa a ser composta por duas frentes de desenvolvimento, o econômico e o ambiental e contempla ações que possam de fato sustentar-se ao longo prazo. Braungart, McDonough e Bollinger (2006) concebem a ecoeficiência como uma estratégia de ação social, pela qual a finalidade é reduzir o uso de materiais na economia com vistas a minimizar impactos ambientais indesejáveis e produzir níveis relativamente mais altos de riquezas econômicas, que deverão ser distribuídas de maneira mais justa.

Já a inserção econômica, doravante denominada inserção socioeconômica, por ser o termo semanticamente mais adequado à integração proposta, seguindo orientações de Bujes (2008), refere-se à promoção de mais justiça e igualdade de forma que haja possibilidade de crescimento real em todos os setores abrangidos pela organização, eliminando, gradativamente, os déficits sociais apresentados nos indicadores discutidos mundialmente. Observa-se também que o fenômeno inserção socioeconômica, compreende que a perspectiva econômica é também vital para o desenvolvimento social, sendo os elementos social e o econômico formas de desenvolvimento complementares. Alguns autores (BUJES, 2008; ELKINGTON, 1999; SAVITZ; WEBER, 2006) citados na pesquisa teórica reduzem esse fenômeno à inserção social apenas, contudo, entende-se que no sistema econômico vigente inserir-se socialmente está intrinsecamente atrelado a uma condição financeira mínima, assim destaca-se a presença da variável econômica no termo.

Por fim, percebe-se que as questões ambientais influenciam fortemente na qualidade de vida da comunidade na qual a organização está inserida, desta forma, para Nusdeo (2002) a justiça socioambiental refere-se ao zelo para que grupos mais vulneráveis de uma dada comunidade, como a população de baixa renda, determinados grupos raciais ou étnicos, entre outros, não sejam afetados desproporcionalmente pelos efeitos negativos da legislação ambiental. Além disso, a justiça socioambiental prima pelo direito de participação efetiva nas decisões que os afetam e pela compensação dos constrangimentos por eles suportados. Contudo, a justiça socioambiental, dentro do contexto organizacional, defende a igualdade entre todos os envolvidos, seja a equitativa divisão dos benefícios ou também dos malefícios. Assim, não é relevante a posição hierárquica do indivíduo na organização no que se trata da equidade de impactos, ou seja, todos os membros desta organização devem de forma igual ter acesso aos benefícios e aos malefícios ambientais e/ou sociais causados pelas atividades organizacionais. Enfatiza-se que uma situação de equidade no ambiente de trabalho não se trata de ambientes iguais, mas de condições mínimas respeitadas, de modo contextualizado.

A justiça socioambiental não admite, por exemplo, que um trabalhador do chão de fábrica trabalhe em uma sala igual à do presidente da organização. Na realidade, a luta reside em que todos tenham direito a respirar um ar de mesma qualidade, trabalhar em níveis de temperatura e de ruído não prejudiciais à saúde e confortáveis, isto é, defende-se que todos compartilhem dos benefícios e malefícios das atividades organizacionais.

Desta forma, o framework proposto é dotado de racionalidade intencional e limitada, pois como sugere a teoria do agir organizacional de Maggi (2006), a organização é concebida como um agir social, e essa concepção não separa a organização dos sujeitos agentes que atuam e desenvolvem o processo de tomada de ações e decisões. É nesse sentido, observando que são os sujeitos que tomarão ações e decisões organizacionais, que a estrutura possui uma racionalidade intencional, pois está orientada em direção a um objetivo com base no sentido intencional dos sujeitos, seus conhecimentos e atitudes, e é também limitada porque toda esta razão humana o é, refletindo, assim, no modelo proposto e na organização. 


\section{CONSIDERAÇÕES FINAIS, IMPLICAÇÕES PARA AS ORGANIZAÇÕES E SUGESTÕES PARA ESTUDOS FUTUROS}

Ao constatar-se que a seara organizacional carece de orientações no que tange aos caminhos para se chegar à sustentabilidade, o presente artigo teve como objetivo, a partir da elaboração de um framework, suprir parcialmente esta lacuna. Articularam-se conceitos e chegou-se à estrutura conceitual já explicada.

$\mathrm{Na}$ visão dos autores deste trabalho, a referida estrutura oferece uma nova perspectiva para o acontecimento da Sustentabilidade Organizacional (SO), pois delimita conceitos centrais a serem abordados e desenvolvidos no caminho para tal. O necessário equilíbrio das perspectivas econômica, ambiental e social veio à tona. Ao buscá-lo, definiu-se cada uma dessas perspectivas e suas exigências para a composição da sustentabilidade organizacional. Isso permitiu estabelecer as bases compreensivas da SO, delimitando o que realmente deve ser perseguido. Portanto, o grande avanço em relação aos modelos e às explicações já existentes está na definição conceitual clara e concisa dos elementos constituintes do processo, bem como na identificação da forma de interação destes.

Uma vez conhecido o sequenciamento proposto pelo framework, é possível planejar e compreender seu equilíbrio e balanceamento conforme as exigências da sustentabilidade. Temse também como contribuição da construção deste framework a aproximação da Teoria do Agir Organizacional como uma teoria de base que permite suprir clássicas lacunas de outras abordagens de sustentabilidade organizacional. Por ela foi possível ressaltar a racionalidade intencional e limitada envolvida, raramente evidenciada por outros modelos; e a visão da sustentabilidade organizacional como um processo de ações e decisões intencional, nunca finalizado. Isso permitiu enfatizar que tanto a organização quanto a sustentabilidade organizacional são processos que existirão e estarão em mudança por meio da variável tempo, nesse sentido dependerão de indivíduos ativos revendo periodicamente o processo.

Dessa forma, ao considerar o entendimento de que tanto a organização quanto a Sustentabilidade Organizacional são processos de ações e decisões, em constante construção e mutação e, ainda, com vistas ao exposto no estudo, é possível concluir que a Sustentabilidade Organizacional não deve ser trabalhada como um projeto à parte, demandante de esforços específicos, muito pelo contrário, deve integrar os processos organizacionais tendo os indivíduos como atores centrais neste caminho.

Ao buscar estruturar os fundamentos conceituais da sustentabilidade organizacional, acreditase que suas definições sejam mais bem esclarecidas e difundidas. Desse modo, será permitido às organizações o desenvolvimento de ações estratégicas voltadas à sustentabilidade organizacional de maneira coerente e aprimorada. Ademais, se comprovada e explicada a relevância da complementaridade e a integração dos fenômenos abarcados neste estudo, almeja-se que as organizações tenham à sua disposição uma base de análise que orientará os gestores no alcance da efetividade e de melhores práticas de sustentabilidade, de modo a subsidiar modelos de gestão, instrumentos de mensuração e avaliação, conscientizando seus agentes, além dos atores sociais envolvidos em sua cadeia de atuação. No Quadro 3 são sintetizados algumas possíveis implicações deste estudo para a prática organizacional.

Quadro 3 - Implicações para a prática organizacional

\begin{tabular}{|l|l|}
\hline Âmbito da implicação & \multicolumn{1}{c|}{ Descrição } \\
\hline Gestão & $\begin{array}{l}\text { Potencial para alcançar melhores práticas de sustentabilidade, por meio de } \\
\text { modelos de gestão, indicadores e instrumentos de avaliação conceitualmente } \\
\text { coerentes e holísticos. }\end{array}$ \\
\hline Alinhamento estratégico & $\begin{array}{l}\text { O alinhamento da estratégia organizacional com as premissas da } \\
\text { sustentabilidade pode melhor orientar os gestores, a fim de balancear } \\
\text { aspectos sociais, ambientais e econômicos com os objetivos organizacionais } \\
\text { na tomada de decisão. }\end{array}$ \\
\hline Recursos humanos & $\begin{array}{l}\text { A possibilidade de atrair e desenvolver pessoas com base na sustentabilidade } \\
\text { auxilia na incorporação desta na cultura organizacional, fazendo com que } \\
\text { a sustentabilidade seja efetivamente uma nova forma de gestão e não } \\
\text { apenas soluções incrementais. }\end{array}$ \\
\hline
\end{tabular}


Alianças e

relacionamento com

stakeholders
A formação de alianças com stakeholders diversos auxilia o alcance de maiores níveis de sustentabilidade, principalmente no que tange às dimensões sociais e ambientais, nas quais os grupos externos à organização geralmente detêm maior primazia que ela própria.

Fonte: Elaborado pelos autores.

Muito embora o framework apresentado norteie as ações organizacionais de uma perspectiva macro, é perceptível que as implicações para a prática organizacional mostram-se internamente pontuais. Para que se avance nesta discussão, admite-se e recomenda-se que futuros estudos possam avançar na instrumentalização desta estrutura. Em um primeiro momento, por meio da criação de indicadores capazes de mensurar a ecoeficiência, a justiça socioambiental e a inserção socioeconômica e, posteriormente, por meio da elaboração de instrumentos capazes de orientar o desenvolver equilibrado destes fenômenos.

\section{REFERÊNCIAS}

ABBAGNANO, N. Dicionário de filosofia. 5. ed. São Paulo: Martins Fontes, 2007.

ATKINSON, G.; HETT, T.; NEWCOMBE. J. Measuring 'corporate sustainability'. Social Research, p.1-38, 1999.

AZAPAGIC, A. Systems approach to corporate sustainability: a general management framework. Institution of Chemical Engineers, v.81, p.303-316, 2003.

BARKEMEYER, R.; HOLT, D.; PREUSS, L.; TSANG, S. What Happened to the 'Development' in Sustainable Development? Business Guidelines Two Decades After Brundtland. Sustainable Developlment, 2011.

BARONI, Margaret. Ambiguidades e deficiências do conceito de desenvolvimento sustentável. Revista de Administração de Empresas, v.32, n.2, p.14-24, 1992.

BRAUNGART, M.; MCDONOUGH, W., BOLLINGER, A. Cradle-to-cradle design: creating healthy emissions e a strategy for eco-effective product and system design. Journal of Cleaner Production, 2006.

BUJES, M. I. E. Para pensar pesquisa e inserção social. Revista Eletrônica de Educação, v.2, n.2, 2008.

BORIM-DE-SOUZA, R. O alinhamento entre sustentabilidade e competências em contexto organizacional. Dissertação (Mestrado em Administração). Universidade Estadual de Maringá (UEM) / Universidade Estadual de Londrina (UEL), Londrina, 2010.

CALLADO, A.L.C Modelo de mensuração de sustentabilidade empresarial: uma aplicação em vinícolas localizadas na Serra Gaúcha. Tese (Doutorado em Agronegócios). Universidade Federal do Rio Grande do Sul. Porto Alegre, 2010.

CELLA-DE-OLIVEIRA, F. A. Ecoeficiência: competência para a sustentabilidade organizacional. Um estudo de caso na indústria de acumuladores de energia. (Mestrado em Administração). Universidade Estadual de Londrina (UEL), Londrina, 2012.

DIAS, B.G.; MUNCK, L.; BANSI, A. C.; CELLA-DE-OLIVEIRA, F. A. Bases Compreensivas da Sustentabilidade Organizacional: a Proposição de uma Estrutura Conceitual (Framework). In: XIV Seminários em Administração. Anais... XIV SEMEAD, São Paulo, 2011.

DONALDSON, L. Teoria da Contingência Estrutural. In: CLEGG, S. R.; HARDY, C.; NORD, W. R. Handbook de estudos organizacionais, v.1. São Paulo: ATLAS, 1999.

DYLLICK, T.; HOCKERTS, K. Beyound the business case for corporate sustentability. Business Strategy and the environment, v.11, p.130-141, 2002.

ELKINGTON, J. Cannibals with forks: the triple bottom line of 21st century business. Oxford: Capstone Publishing Limited, 1999. 
FERGUS, A. H. T.; ROWNEY, J. I. A. Sustainable development: lost meaning and opportunity? Journal of Business Ethics, v. 60, p. 17-27, 2005.

FERNANDES, M. Desenvolvimento Sustentável: antinomias de um conceito. In: FERNANDES, M.; GUERRA, L. (Orgs.). Contra-Discurso do Desenvolvimento Sustentável. Belém: Associação de Universidades Amazônicas, 2003.

GALBRAITH, J.R.; KAZANJIAN, R.K. Strategy implementation: structure, systems and process. St. Paul: West Publisher, 1986.

GIL LAFUENTE, A. M.; PAULA, L. B. La gestion de los grupos de interes: una reflexion sobre los desafios a los que se enfrentan las empresas en la busqueda de la sostenibilidad empresarial. Revista de Metodos Cuantitativos para la Economia y la Empresa, n.11, p.71-90, 2011.

GLADWIN, T. N.; KENELLY, J. J.; KRAUSE, T. S. Shifting paradigms for sustainable development: implications for management theory and research. Academy of Management, v. 20, n. 4, p. 874-907, 1995.

HARDING, S.; LONG T. Proven management tools. Great Britain: Gower, 1998.

HOFF, D. N. A construção do desenvolvimento sustentável através das relações entre as organizações e seus stakeholders: a proposição de uma estrutura analítica. Tese (Doutorado em Agronegócios). Universidade Federal do Rio Grande do Sul, Porto Alegre, 2008.

JABAREEN, Y. A new conceptual framework for sustainable development. Environment, Development and Sustainability, v.10, n.2, p.179-192, 2006.

Building a conceptual framework: philosophy, definitions, and procedure. International Journal of Qualitative Methods, v.8, n.4, p.49-62, 2009.

JACOBI, P. Educar para a Sustentabilidade: complexidade, reflexividade, desafios. Educação e Pesquisa. FEUSP, v.31, n.2, 2005.

JAMALI, D. Insights into the triple bottom line integration from a learning organization perspective. Business Process Management Journal, v.12, n.6, p.809-821, 2006.

JIMÉNEZ HERRERO, L.M. Desarrollo sostenible: transición hacia la coevolución global. Madrid: Pirámide Ediciones, 2000.

KRAJNC, D.; GLAVIC, P. A model for integrated assessment of sustainable development. Resources, Conservation and Recycling, v.43, n.2, 2005.

LAVILLE, É. A empresa verde. São Paulo: ÕTE, 2009.

LÉLÉ, S. M. Sustainable development: a critical review. World Development, v.19, n.6, p.607-621, 1991.

LEMME, C. F. O valor gerado pela sustentabilidade corporativa. In: LINS, L. ; ZYLBERSZTAJN, D. Sustentabilidade e geração de valor: a transição para o século XXI. Rio de Janeiro: Elsevier, 2010.

LENZI, C. L. Sociologia Ambiental: risco e sustentabilidade na modernidade. Bauru: EdusC, 2005.

LINS, C.; ZYLBERSZTAJN, D. Sustentabilidade e geração de valor: a transição para o século XXI. Rio de Janeiro: Elsevier, 2010.

LORENZETTI, D. H.; CRUZ, R. M.; RICIOLI, S. Estratégia empresarial e sustentabilidade: um modelo integrador. Revista da Pós-graduação: Administração, Osasco, v.2, n.3, p.33-57, 2008.

MACHADO-DA-SILVA, C. L. e GONÇALVES, S. A. Nota técnica: A teoria institucional. In: CLEGG, S. R.; HARDY, C.; NORD, W. R. Handbook de estudos organizacionais. v.1, São Paulo: ATLAS, 1999.

MAGGI, B. Do agir organizacional. São Paulo: Edgard Blucher, 2006.

MEADOWS, D. H.; MEADOWS, D. L.; RANDERS, J. Beyond the limits: confronting global collapse, envisioning a sustainable future. Chelsea Green Publishing, 1992.

MENEGHETTI, F. K. O que é um ensaio teórico? Revista de Administração Contemporânea - RAC. v.15, n.2, p.320-332, 2011. 
MONTIBELLER FILHO, G. Empresas, desenvolvimento e ambiente: diagnóstico e diretrizes de sustentabilidade. Barueri: Manole, 2007

MUNCK, L.; MUNCK, M. M. G.; BORIM-DE-SOUZA, R. B. Sustentabilidade Organizacional: A Proposição de uma Framework Representativa do Agir Competente para seu Acontecimento. Gerais: Revista Interinstitucional de Psicologia, v. 4, n. 2, Ed. Especial, p.147-158, 2011.

MUNCK, L. BORIM-DE-SOUZA, R. B. Responsabilidade social empresarial, sustentabilidade organizacional e desenvolvimento sustentável: a proposição de uma hierarquização conceitual. Revista brasileira de estratégia - REBRAE, v.2, p.12-29, 2009a.

Gestão por competências e sustentabilidade empresarial: em busca de um quadro de análise. Gestão e Sociedade, v.3, n.6, p.254-287, 2009b.

NUSDEO, A. M. O. Defesa da concorrência e globalização econômica: o controle da concentração de empresas. São Paulo: Malheiros, 2002.

OSORIO, L. A. R.; LOBATO, M. O.; CASTILLO, X. A. Debates on sustainable development: towards a holistic view of reality. Environment, Development and Sustainability, v.7, p.501-518; 2005.

PINHEIRO DE LIMA, E.; LEZANA, A. G. R. Desenvolvendo um Framework para Estudar a Ação Organizacional: das Competências ao modelo organizacional. GESTÃO \& PRODUÇÃO, v.12, n.2, p.177-190, 2005.

RANSBURG B.; VÁGÁSI M. Concepts and standards for the corporate internalization of sustainable development. Periodica Polytechinica Social Management Sciences, v.15, n.2, p.43-51, 2007.

REDCLIF, M. R. Sustainable development (1987-2005) - an oxymoron comes of age. Horizontes Antropológicos, Porto Alegre, n. 25, p. 65-84, 2007.

SAVITZ, A. W.; WEBER, K. The triple bottom line: how today's best-run companies are achieving. San Francisco: John Wiley \& Sons Inc., 2007.

SHEHABUDDEEN, N.; PROBERT, D.; PHAAL, R. Representing and approaching complex management issues: part 1 - role and definition. Working Paper UC, Cambridge, 2000.

SIENA, O. Método para avaliar desenvolvimento sustentável: técnicas para escolha e ponderação de aspectos e dimensões. Revista Produção, v.18, n.2, 2008.

SILVA, L. S. A., QUELHAS, O.L.G., Sustentabilidade empresarial e o impacto no custo de capital próprio das empresas de capital aberto. Gestão \& Produção, v.13, n.3, p.385-395, 2006.

STUBBS, W.; COCKLIN, C. Conceptualizing a 'Sustainability Business Model'. Organization \& Environment, v. 21, n.2, p. 103-127, 2008.

VAN BELLEN, H. M. Indicadores de sustentabilidade - um levantamento dos principais sistemas de avaliação. Cadernos EBAPE.BR, v.2, n.1, 2004.

VOS, R. O. Defining sustainability: a conceptual Orientation. Journal of Chemical Technology and Biotechnology, v. 82, n. 4, p. 334-339, 2007.

WEBER, M. The theory of social and economic organization. Oxford University Press, New York, 1964.

WORLD COMISSION ON ENVIRONMENT AND DEVELOPMENT - WCED. Our common future: the Brundtland report. Oxford: Oxford University Press, 1987. 